\section{俩 Heighten Science \\ P U B L I C I T I O N S Corporation \\ ISSN \\ 2573-1726}

\title{
Progresses of the Badminton equipment relate to exercise: Some training aspects
}

\author{
Zhi Qiang Liang ${ }^{1,2}$ and Jian She Li ${ }^{1,2 *}$ \\ ${ }^{1}$ Faculty of Sports Science, Ningbo University, 315211, China \\ ${ }^{2}$ Research Academy of Grand Health, Ningbo University, 315211, China
}

\begin{abstract}
*Address for Correspondence: Jian She Li, Faculty of Sports Science, Ningbo University, 315211, China, Email: lijianshe@nbu.edu.cn

Submitted: 20 December 2017

Approved: 04 January 2018

Published: 05 January 2018

Copyright: @ 2018 Liang ZQ, et al. This is an open access article distributed under the Creative Commons Attribution License, which permits unrestricted use, distribution, and reproduction in any medium, provided the original work is properly cited
\end{abstract}

Keywords: Research advancements; The role; Badminton equipment; Sports training

\section{Abstract}

Background: With the development of sports science and badminton equipment, the roles of badminton shoes, such as to alter lower - extremity biomechanical parameters, prevent sports injuries and enhance performance, were confirmed by a mass of studies.

Methods: In this study, a serial of methods including literature review, visualization analysis, mathematical statistics, are used to describe the progresses of the badminton shoes relate to exercise in some training aspects, which can be searched by CNKI and SCOPUS databases.

Results: Among the exiting research, most mainly focused on evaluation and design of badminton shoes, sports injuries and performance, some have tested and verified the roles mechanism of badminton shoes. However, there are still some disadvantages to can't ignore, such as the quantities of studies the designed level and the mechanism exploration.

Conclusions: To sum up, the roles of the badminton shoes in sports training still need to be explored and confirmed.

\section{Introduction}

With the progress of time and the development of technology, the high-tech badminton equipment takes an increasingly important role in general fitness and athletics [1]. Badminton has been attracted much attention, especially after the Barcelona Olympic Games in 1992 [2]. It is a fast-non-contact racket sports event, which needs lower and upper extremities of athlete to execute varieties of postural movements in a very short period of time [3]. From view of sports biomechanics, a series of basic movements involve high-speed and unsymmetrical movements of different orientation [4], which can produce high rates of load on lower extremities of badminton player and have potential to result in sports injuries [5,6], especially on limbs and feet of player [7,9]. Good sport shoes have effects on enhanced performance, reduced sport injury and attenuation shock [4], owing to the special effects of shoes, recently researches have investigated badminton shoes. For example, the study by Cavanagh et al. [8], in early 1980`s indicated that badminton shoes could reduce movement-related injuries; and Goh et al. [10], suggested that as one of injury factors, footwear was linked with badminton injury rates; Wei [4], a Chinese scholar, pointed that wearing badminton shoes could enhance effects of sports performance and prevent and reduce the risk of sports injuries. Based on the above researches, this study mainly reviewed the advancements of badminton shoes in design, performance, sport injury and evaluation around the world; and it is intended to offer some valuable references for design, performance, prevention of injury of badminton shoes and sports biomechanics in further studies. 


\section{The emergency of badminton shoes and comfort}

Benno et al. [11], would development progress of sport shoes divide into three sections that the past, the present and the future; meanwhile, they pointed that initial relevant work mainly concentrated on running filed, and research of other sports within badminton emerged in the second section that the present; it is interesting, however, shoes comfort also emerged in this section $[11,12]$.

As the development of sports science and the broad use and research of shoes in sport field, badminton shoes gradually became attractive to sport scientists, especially movement scientists [11]. The relevant researches between the sports training and the badminton shoes can be summarized as follows: 1 ) the alteration of lower-extremities biomechanical parameter [13-15], 2) the assessment of badminton shoes; 3) the relationship between badminton shoes with performance; 4) the application for injury prevention. These four sections are a mere summary of collection literatures, however, no similar finding is found at among the previous research, and more relevant work is still needed.

Shoes comfort is one of the important characters of sport shoes, the previous research indicated that poor comfort could cause a series of problems; for example, shoes with poor in-shoe and overall fit might lead to foot problem and tiredness or foot discomfort [16], poor medial-lateral stability might influence athletic performance in training and competition [17]. These shortcomings of shoes comfort that can be enhanced by improving perceived footwear cushioning, fit and in-shoe climate [18]. However, there is rarely relevant research about comfort of badminton shoes and only one research in our collection literatures, which is Hong et al. [12], discussed the relationship between the usage time and direction change performance and the comfort perception of badminton shoes, meanwhile pointed that shoe usage time could alter comfort perception but not in direction change performance.

\section{A current review of the research on badminton shoes}

We collected 37 relevant kinds of literature in totally; 8 in Chinese and 29 in English. The search range involved: 1) journals (Table 1); 2) conference papers (IEEE International Conference on Industrial Technology; International Symposium on Biomedical Engineering and Medical Physics; Ifmbe Proceedings; Proceedings of the 7th symposium on Footwear Biomechanics; International Conference on Sport Science and Computer Science; 2013 International Conference on Sport Science and Computer Science; 3rd International Conference on Computer-Aided Design, Manufacturing, Modeling and Simulation); 3) publications (Diagnosis and Management of Marfan Syndrome; Athletic Footwear and Orthoses in Sports Medicine). The research keywords were "badminton shoes" and "badminton footwear" (shoes, solo).

In this study, we made a statistical analysis on 37 literatures regarding badminton shoes (Figure 1). From the time curve, we found that the number of papers regarding badminton shoes has been increasing nearly 1 literature per year. The number of relevant studies into badminton shoes has been rapidly developed from 2009; particularly, it reached up to peak value in 2013 and 2014. In the last ten years, views regarding badminton shoes gradually start various, and they involved fields of the evaluation of badmintons shoes and solo, the role of badminton footwear on sports biomechanics, the design of badminton footwear, the improvement of player performance and the prevention of injury (Table 2). The various kinds of researches will provide persistent energy for the development of badminton shoes.

In more than 30 years development, the field of badminton shoes research has been formed 182 perspectives (Figure 2). From figure 2, 10 nodes-badminton, 
Table 1: The journal and number of paper published regarding badminton shoes.

\begin{tabular}{|c|c|c|}
\hline Serial number & Journal name & Number of paper published \\
\hline 1 & Footwear Science & 5 \\
\hline 2 & Plos one & 2 \\
\hline 3 & Contemporary Sports Technology & 2 \\
\hline 4 & Sports Biomechanics & 1 \\
\hline 5 & Journal of Chemical and Pharmaceutical Research & 1 \\
\hline 6 & Journal of Sports Sciences & 1 \\
\hline 7 & Applied Mechanics and Materials & 1 \\
\hline 8 & Journal of Medical Biomechanics & 1 \\
\hline 9 & Journal of Applied Biomechanics & 1 \\
\hline 10 & China Sport Science & 1 \\
\hline 11 & Deutsche Zeitschrift fuer Sportmedizin & 1 \\
\hline 12 & Physical Therapy in Sport & 1 \\
\hline 13 & Orthopadische Praxis & 1 \\
\hline 14 & Sports Medicine & 1 \\
\hline 15 & Wsa Performance \& Sports Materials & 1 \\
\hline 16 & Journal of Tianjin University of Sport & 1 \\
\hline 17 & Chinese Journal of Clinical Medicine & 1 \\
\hline 18 & Shanxi education & 1 \\
\hline 19 & Fujian Sports Science and Technology & 1 \\
\hline 20 & Process and Technology & 1 \\
\hline 21 & China Invention \& Patent & 1 \\
\hline 22 & Technology & 1 \\
\hline sum & 22 & 28 \\
\hline
\end{tabular}

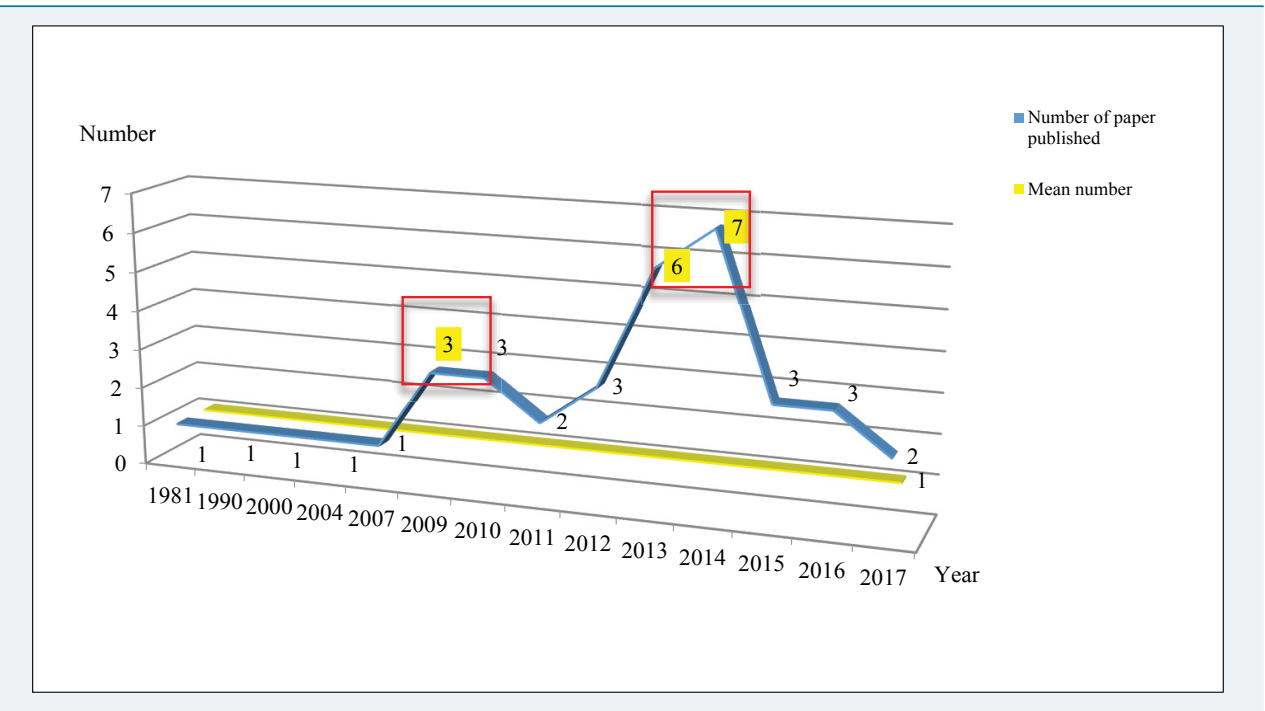

Figure 1: The number of papers regarding badminton shoes.

biomechanics, racquet sport, footwear, human, male, shoe, ground reaction force, physiology and biophysics - have high occurrence frequencies and are burst out; and it indicates that those nodes are currently research hot points of badminton shoes. Some perspectives in hot points - badminton, biomechanics, shoe, physiology, racquet sport - are emphasized by purple circle at the surrounding of nodes (Table 3); and they are indicated that these perspectives have more influences in badminton shoes field than other perspectives. We find that these 10 hot points are mainly involve fields-sports biomechanics, sports physiology, sports training, shoes manufacture. 
Table 2: The perspectives of badminton shoes involved field of research.

\begin{tabular}{|c|c|c|}
\hline Fields & Quantity & Percentage (\%) \\
\hline the evaluations of badminton shoes and solo & 10 & 27 \\
\hline the improvement of player performance & 10 & 27 \\
\hline the prevention of injury & 9 & 24 \\
\hline the design of badminton footwear & 6 & 16 \\
\hline the role of badminton footwear on sports biomechanics & 2 & 5 \\
\hline
\end{tabular}

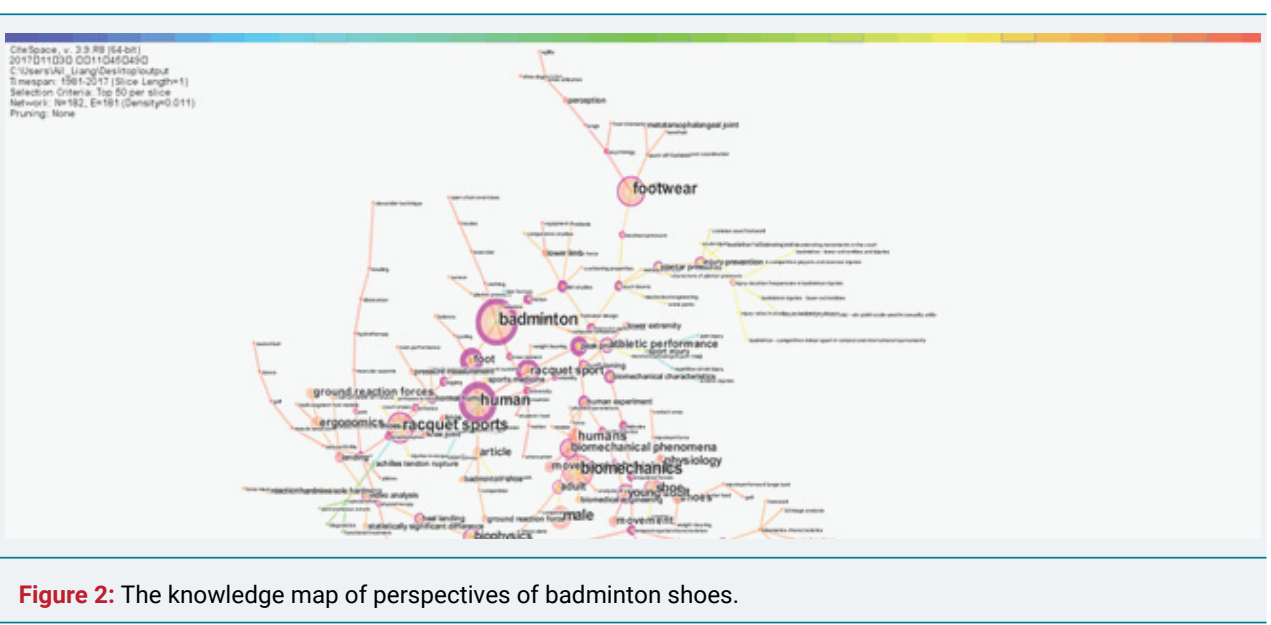

Table 3: The frequency and centrality of perspectives of badminton shoes.

\begin{tabular}{|c|c|c|c|}
\hline Number & Nodes & Frequency & Centrality \\
\hline 1 & Badminton & 9 & 0.61 \\
\hline 2 & Biomechanics & 8 & 0.52 \\
\hline 3 & Racquet sport & 7 & 0.10 \\
\hline 4 & Footwear & 7 & 0.07 \\
\hline 5 & Human & 7 & 0.01 \\
\hline 6 & Male & 6 & 0.00 \\
\hline 7 & Shoe & 5 & 0.33 \\
\hline 8 & Ground reaction force & 4 & 0.06 \\
\hline 9 & physiology & 4 & 0.11 \\
\hline 10 & biophysics & 4 & 0.01 \\
\hline
\end{tabular}

Major aspect of research in badminton shoes

The previous studies have demonstrated that badminton shoes have good effects in aspects of technical improvement, shoes design, and prevention of lower-extremity injury [14]. This study reviewed the course of over thirty years development of badminton shoes, we found that relevant researches mainly focused on sports biomechanics, medicine, sports training and others; therefore we divided these relevant researches into four major aspects of research: 1) the evaluation of badminton shoes, 2) the injury prevention, 3) the design of shoes, 4) the athletic performance.

\section{The evaluation of effect of badminton shoes}

Badminton shoes could produce greater influence on the athletic performance of players; sports training and sport science experts have often been using a serial of lunge movement skill to evaluate the effects of badminton shoes that involve shoe, sole, outsole and comfort [19].

The previous studies suggested that badminton shoes with greater shoe sole or bending stiffness could produce an influence on biomechanical parameters of feet [20], 
stiffening the shoe sole had enhanced sprinting and jumping performance of player [21]. However, there are three literatures regarding sole of badminton shoes in our collection literatures; for example, Ma et al. [22], and Mei et al. [23], used biomechanical methods to test biomechanical reaction of the badminton shoe hardness, they indicated that the lower hardness sole could produce the less peak ground reaction forces and the higher harness sole could produce less heel landing time. It indicated that badminton shoes not only shall protect the foot joints and muscles in exercise or competition, but also improve the athlete's reaction speed. Lin et al. [24], discussed the influence of midsole thickness on biomechanical parameters of lower extremity, biomechanical parameters in this study indicated that badminton shoes with thicker midsoles may be associated with a greater risk of soft tissue injury in overuse and could offer support for feet. It found that thicker midsoles should take a role in minimizing the risk of injury under overuse condition.

In our study, we systematically review on influence of badminton shoes on human body, including joints and comfort perception. Yong et al. [25], made a study regarding exploration of biomechanical characteristics of MP (metatarsophalangeal joint) and the effects of different footwear on these characteristics, and pointed that MP had an important role on feet functions, the effects of footwear on this joint should not be neglected, and its functionality should be concerned when designing shoes. For comfort perception of badminton shoes, Hong et al. [12], carried out a study about relationship between shoe usage time with comfort perception; they pointed that usage time of shoe could play a role in shoe comfort perception, but no difference in direction change performance. Recently, Park et al. [26], study indicated that forefoot bending stiffness would influence comfort perception of badminton shoes, but would not influence lower limbs biomechanical parameters and performance.

Li et al. [27], made a pilot study regarding outsole of badminton shoes, results suggested that professional badminton shoes had a better ground grip ability and certain advantages in improving performance than the ordinary shoes, and they had the same level in the aspect of cushioning property. Park et al. [28], also suggested that slightly modification of outsole stiffness would change the lower-extremity biomechanical parameters.

Thus, despite the previous studies which evaluating badminton shoes from sole, outsole and comfort perception, but the quantities of relevant studies are still less than other sport shoes, and still need to be developed.

\section{The relationship between badminton shoes and injury prevention}

The previous studies suggested that badminton participation could cause some injuries of lower extremity [9]. Furthermore, the most common injuries are located at feet and ankle [29]; these injuries could be prevented and rehabilitated by different ways and one option is wearing suitable shoes [30,31]. This perspective that "shoe could prevent and recovery injury" had been already reached an agreement, however, there were a small quantity of relevant studies. This phenomenon supported the conclusion that Uffe and Soren pointed in 1990 that badminton had received little sports medical interest [29].

There are several updated relevant studies in our collection literatures and summarized as following: $\mathrm{Hu}$ et al. [32], studied in 2015 regarding distribution characteristics of plantar loads under wearing shoes condition, and pointed that it is very important to comprehensively evaluate the lower-extremity biomechanics, provide the further insights into the biomechanics of sports injuries, and it would provide more information for prevention of sports injuries. Yun-Han et al. [33], in 2016 suggested that the pain in the Achilles tendon was common among middle-age amateur badminton players, and wearing suitable badminton shoes and enough preparing 
activities could effectively decrease incidence rate of pain of Achilles tendon in sport, Which was also supported Wang [34] and Yang and Shu [35], regarding badminton injuries; in the studies, they all suggested that wearing suitable badminton shoes was an effectively way for sports injuries prevention. In our study, we also collected some studies showing relationship between badminton shoes and sports injuries indicated that suitable shoes as a factor of sport-related injuries prevention, but no experimental studies that verify badminton shoes how to make a role in prevention sports injuries.

The design of badminton shoes

The design of badminton shoes is one of the major aspects of badminton shoes research field. From the industrial revolution to the present, sports shoe had taken a great change; meanwhile, injury prevention, performance, and comfort were three characteristics that could distinguish the functional and non-functional sports shoes, due to be influenced by previous of health, racquet sports, injury prevention, and limited scientific research [36]. Badminton shoes as one of the types of the sports shoes, it is necessary to take these items into consideration while being design; to reveal advancement of design of badminton shoes, we summarize relevant studies as following:

The earliest study regarding design of badminton shoes is Penny Leese`s [37] study in 2010, he suggested that badminton shoes concentrate on exciting color and material combinations due to be inspired by tennis and golf. Later, relevant studies started gradually for example, Fu [14] made a biomechanical study in 2011, pointed that the metatarsal heads and lateral of heel were the most contacting regions of foot; and suggested design of shoe sole should use different materials to disperse pressures of foot, besides, in order to prevent potential injuries, stability of rear foot also need to be considered in footwear design. In 2012, Fu et al. [38], made a study about the plantar pressure of badminton player, found the forefoot medial metatarsal, the first toe, the first metatarsal and second metatarsal had the higher pressure; the issue of these biomechanical parameters cannot be missed in design of suitable shoes, which could disperse pressure of part foot.

There are also two relevant studies in 2012, respectively: Li and $\mathrm{Du}$ [39] investigated the science and technology of badminton shoes of four companies: Lining, Yonex, Asics, and Victor; and pointed that the higher science and technology in design of badminton shoes not only contribute to performance, but also effectively reduce sport-related injuries. Chen and Zhu [40] analyzed on design of Lin Dan`s badminton shoes, suggested that special design in appearance, structure and processing technic were the biggest difference to compare with common badminton shoes. Recently, Lam et al. [41], explored the influence of shoe heel curvature on biomechanical parameters of lower extremities, result showed that shoe heel curvature played some role in variation of biomechanical parameters, and the difference in parameters may provide useful information for design of badminton shoes and prevention of injuries. This finding supported influence results of badminton shoe heel on lower extremities by Li et al. [15].

As what we summarized, it's easy to find out that the previous studies mainly focused on using theories and experiments to state the design of badminton shoes in detail. However, the quantity of used experimental studies to confirm rationality of design badminton shoe are too less, and studies only involve biomechanical field. Further studies need more experimental study and other fields to confirm the rational design of badminton shoes.

The badminton shoes and performance

Up to now, there are various studies to verify the close relationship between badminton shoes and performance from aspects of sport training and injury, shoe 
design, shoe evaluation and the others. We also collected some relevant literatures, involved the fields of movement skill, shoe structure and locomotivity; and they are listed as follows:

The biomechanical methods are mainly research methods to analyze on the relationship between badminton shoes and performance. JiSeon et al. [42], explored relationship between the torsion of badminton shoes and the athletic performance; results showed that the shoe hinder might impact on movement of feet, causing muscle fatigue, reduce the comfort and performance; however, the flexible shoe with lower torsion is more contributing to accomplish various movements and enhance agility performance. And Ryue et al. [43], analyzed the effects of different heel shape on biomechanical parameters of lower extremities, pointed that different heel shapes would alter biomechanical parameters of lower extremities, and the rounded heel was more superiority than other shape heels.

There are three relevant studies associated with sports straining, respectively. Hong et al. [13], analyzed the biomechanical characteristics of four lunges under wearing different shoes condition, pointed that the left-forward lunge had higher external and insole loadings than others during heel impact, and the repetitive lunge movements were potential risk factors of sport-related injuries; for the reason that the leftforward lunge became a critical movement for evaluation of badminton performance and footwear. Wei-Jie et al. [44], discussed the influence of different footwear on coordination, results showed that footwear could enhance athlete performance by providing dynamic source, improving velocity and effects of push-off. This result was agreed with research by Wei [4].

From these studies, we know that studies about analysis of movement skill and enhancement of athletic performance are the most majors in badminton shoes field, and most of them are experimental study, especially biomechanical study. This phenomenon also indicates that biomechanics is playing more and more important role in fields of badminton shoes and enhancement of athletic performance.

\section{Conclusion}

With the development of sports science and badminton equipment, increasingly studies indicate that the badminton footwear plays an important role in athletic performance, sport-related injuries prevention and body fitness; besides, the science technology in badminton shoes is higher and more human. However, there are some shortcomings that we cannot ignore: 1 ) the quantities of relevant studies are too less to quickly promote development of badminton shoes; 2) the design level of badminton shoes has the bigger difference with mainstream sport events; 3 ) the mechanism still needs more experiments to explore. To sum up, badminton shoes still need the more relevant studies to explore and confirm.

\section{References}

1. Fu W, Liu Y, Fang Y. Research advancements in humanoid compression garments in sports. Int $\mathrm{J}$ Adv Robotic Sy. 2013; 10: 1-6. Ref.: https://goo.gl/Dt6k9N

2. Mei Q, Gu Y, Fu F, Fernandez J. A biomechanical investigation of right-forward lunging step among badminton players. J Sports Sci. 2016; 35: 457-462. Ref.: https://goo.gl/ZzTNUi

3. Chen B, Mok D, Lee WCC, Lam WK. High-intensity stepwise conditioning programme for improved exercise responses and agility performance of a badminton player with knee pain. Phys Ther Sport. 2015; 16: 80-85. Ref.: https://goo.gl/DhHp7L

4. Wei Y. Effects of sports shoes on metatarsophalangeal joint and rearfoot motion in typical badminton footwork. Chin Sport Sci. 2009; 29: 89-96. Ref.: https://goo.gl/Qq7GxD

5. Shariff $\mathrm{AH}$, George J, Ramlan AA. Musculoskeletal injuries among malaysian badminton players. Singapore Med J. 2009; 50: 1095-1097. Ref.: https://goo.gl/qq1Qw1 
6. Robinson G, O'Donoghue P. A movement classification for the investigation of agility demands and injury risk in sport. Int J Perf Anal Spor. 2008; 8: 127-144. Ref.: https://goo.gl/xXTgWo

7. Xiao YU. The study of athletic injuries for badminton athlete in guangzhou. J Pla Inst Phys Educ. 2005; 24: 100-103. Ref.: https://goo.gl/CndAA9

8. Cavanagh PR, Vandervelde AE. The running shoe book. 1980.

9. Hensley LD, Paup DC. A survey of badminton injuries. Br J Sports Med. 1979; 13:156-160. Ref.: https://goo.gl/FMYNks

10. Goh S, Ali M, Mokhtar A, Mohamed I. Injury risk predictors among student badminton players in a malaysian national sports school: preliminary study. J Sci Med Sport. 2013; 16: 59. Ref.: https://goo.gl/KJt3LM

11. Benno M, Darren S, Gerald C, Kath B. Footwear Research-Past, Present and Future. 2007. Ref.: https://goo.gl/vy3hvN

12. Hong $Y$, Lam WK, Wang S, Cheung TM. Changes in comfort perception and direction change performance of badminton shoes with extensive usage time. Footwear Science. 2016; 8: 13-17. Ref.: https://goo.gl/3pEBi2

13. Hong Y, Wang SJ, Lam WK, Cheung JT. Kinetics of badminton lunges in four directions. J Appl Biomech. 2014; 30: 113-118. Ref.: https://goo.gl/8nRFch

14. Fu WJ. The role of footwear on plantar pressure performance during badminton movements. Appl Mech Mater. 2011; 55-57: 1675-1678. Ref.: https://goo.gl/Mu5mYF

15. Li S, Wu L, Hong Y. The impact of new badminton shoes on the front stride steps. CCCS. 2014 805-810.

16. Lam W K, Sterzing T, Cheung JT. Influence of protocol complexity on fit perception of basketball footwear. Footwear Sci. 2013; 5:155-163. Ref.: https://goo.gl/ymRFG7

17. Mcpoil TG. Athletic footwear: design, performance and selection issues. J Sci Med Sport. 2000; 3 : 260-267. Ref.: https://goo.gl/pLor9P

18. Reinschmidt C, Nigg BM. Current issues in the design of running and court shoes. Sportverletz Sportschaden. 2000; 14: 71-81. Ref.: https://goo.gl/Se85k3

19. Lam WK, Rui D, Yi Q. Ground reaction forces and knee kinetics during single and repeated badminton lunges. J Sports Sci. 2016; 35: 587-592. Ref.: https://goo.gl/WBR9wU

20. Park SK et al. Proceedings of 10th FBG. Tübingen, Germany. 2011: 142-143.

21. Stefanyshyn DJ. Nigg BM. MSSE, 2000; 32: 471-476.

22. Ma JB, Shen WW, Hao Q. Sole Hardness Effect on Typical Badminton Movement. IFMBE. 2013:1012. Ref.: https://goo.gl/BVdnM6

23. Mei Q, Zhang Y, Li J, Rong M. Different sole hardness for badminton movement. J Chem Pharm Res. 2014:632-634.

24. Lin YJ, Chang CC, Lee SC, Hsu WC, Shiang TY, et al. Do thicker midsoles increase shock attenuation and do thin midsoles facilitate propulsion during lunge maneuvers? Footwear design for racketsport industry. IEEE ICIT. 2016: 1578-1584. Ref.: https://goo.gl/bwBfri

25. Wei Y, Liu Y, Fu WJ. The effect of badminton footwear on the metatarsophalangeal joint during push-off in critical badminton footwork. Footwear Sci. 2009; 1: 14-16. Ref.: https://goo.gl/MdFhVc

26. Park SK, Lam WK, Yoon S, Lee KK, Ryu J. Effects of forefoot bending stiffness of badminton shoes on agility, comfort perception and lower leg kinematics during typical badminton movements. Sports Biomech. 2017; 16. 374-386. Ref.: https://goo.gl/4iBCpd

27. Li SD, Gu YD, Lu YC, Li JS. Comparative study of the different outsole effect on badminton movement. Ifmbe Proceedings. 2013; 40: 126-128. Ref.: https://goo.gl/84dXC7

28. Park SK, Lam WK, Ryu JS, Cheung SYJ. Effect of forefoot bending stiffness of badminton shoe sole on lower leg kinematics during match-like situations. Footwear Sci. 2013; 5: 133-135. Ref.: https://goo.gl/XM7WKi

29. Uffe J, Soren W. Injuries in Badminton. Sports Med. 1990; 10: 59-64.

30. Pfoerringer W. Ankle injuries in top sport. Orthopadische Praxis. 1981; 17: 319. 
31. Steinbrueck K. Achilles tendon ruptures in Sports-Epidemiology, topical diagnostic, therapy and rehabilitation-Analysis of 791 cases. Deutsche Z Fuer Sportmedizin. 2000; 51: 154-160. Ref.: https://goo.gl/nsu948

32. Hu X, Li JX, Hong $Y$, Wang L. Characteristics of plantar loads in maximum forward lunge tasks in badminton. Plos One. 2015; 10: 1-10. Ref.: https://goo.gl/WmKKMZ

33. Yun-Han $\mathrm{JI}$, Xin MA, Wang $X$, Huang JZ, Zhang $C$, Chen L, et al. Investigation on the pain in the achilles tendon region in middle-aged amateur badminton players. Chin J Clin Med. 2016; 23: 222 224. Ref.: https://goo.gl/ftkdAE

34. Wang $\mathrm{CL}$. The epidemiological investigation of sports injuries on amateur badminton player in Xian Shanxi educ. 2010; 4: 62. Ref.: https://goo.gl/ZQRm16

35. Yang YX, Shu CN. The exploration about the risk of middle-age people participated sports event of badminton. Contemporary Sports Technol. 2014; 4: 148. Ref.: https://goo.gl/HUAnxJ

36. Bouché RT. Racquet Sports: Tennis, Badminton, Squash, Racquetball, and Handball. Athletic Footwear and Orthoses in Sports Medicine. Springer New York. 2010: 215-223. Ref.: https://goo.gl/TPwqeR

37. Penny, Leese. colour cones back to the slope. WAS. 2010; 16: 42-45. Ref.: https://goo.gl/5UMKoDb

38. Fu W, Liu Y, Li L. The characteristics of plantar pressure in typical footwork of badminton. J Tianjin University Sport. 2012; 27: 511-514. Ref.: https://goo.gl/Q65jtc

39. Li JF, Du H. The advancement of technology of badminton shoes. Contemporary Sports Technol. 2012; 2: 6-7. Ref.: https://goo.gl/CtZaM2

40. Chen LY, Zhu YH. Technology innovation contribute to classic-analysis on Li Dan`s badminton shoes. Chin Invention Patent. 2012: 39-40.

41. Lam WK, Ryue J, Lee KK, Park SK, Cheung JT, et al. Does shoe heel design influence ground reaction forces and knee moments during maximum lunges in elite and intermediate badminton players? PloS One. 2017; 12: 1-13. Ref.: https://goo.gl/Uks9qy

42. Ryue J, Yoon S, Park SK, Thompson M, Lam WK, et al. The relationship between shoe torsion and athletic performance during badminton maneuvers. Footwear Sci. 2011; 3: 142-143. Ref.: https://goo.gl/TC4EMA

43. Ryue J, Lam WK, Cheung J, Lee KK. Effect of shoe heel modifications on shock attenuation and joint loading during extreme lunge movement in elite badminton players. Footwear Sci. 2013; 5: 72-73. Ref.: https://goo.gl/6pK27b

44. Wei-Jie F, Yong W, Yu L. Effects of footwear and barefoot on movement coordination of lower extremities and metatarsophalangeal joints during push-off in badminton footwork. J Med Biomechanics. 2015; 30: 159-166. Ref.: https://goo.gl/utvtYx 